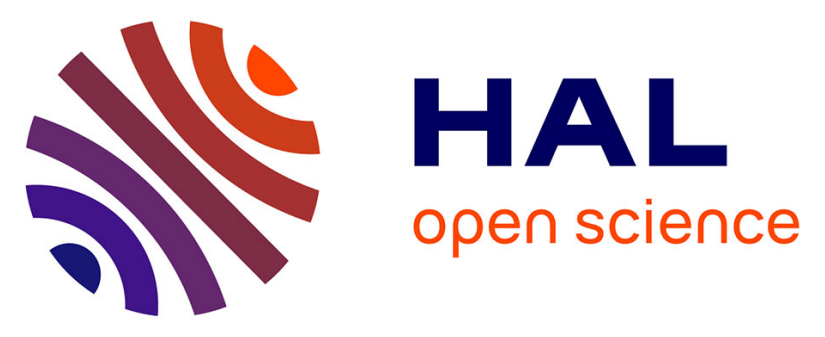

\title{
Adenosine Plasma Level and A2A Receptor Expression in Patients With Cardiogenic Shock
}

\author{
Mélanie Gaubert, Marion Marlinge, François Kerbaul, Noémie Resseguier, \\ Marc Laine, Jennifer Cautella, Charlotte Cordier, Benjamin Colomb, Nathalie \\ Kipson, Franck Thuny, et al.
}

\section{To cite this version:}

Mélanie Gaubert, Marion Marlinge, François Kerbaul, Noémie Resseguier, Marc Laine, et al.. Adenosine Plasma Level and A2A Receptor Expression in Patients With Cardiogenic Shock. Critical Care Medicine, 2018, 46 (9), pp.E874 - E880. 10.1097/CCM.0000000000003252 . hal-01855332

\section{HAL Id: hal-01855332 \\ https://hal-amu.archives-ouvertes.fr/hal-01855332}

Submitted on 29 Mar 2019

HAL is a multi-disciplinary open access archive for the deposit and dissemination of scientific research documents, whether they are published or not. The documents may come from teaching and research institutions in France or abroad, or from public or private research centers.
L'archive ouverte pluridisciplinaire HAL, est destinée au dépôt et à la diffusion de documents scientifiques de niveau recherche, publiés ou non, émanant des établissements d'enseignement et de recherche français ou étrangers, des laboratoires publics ou privés. 


\section{Adenosine Plasma Level and $A_{2 A}$ Receptor Expression in Patients with Cardiogenic Shock}

Crit Care Med. 2018 Jun 19. doi: 10.1097/CCM.0000000000003252. [Epub ahead of print]

Mélanie Gaubert, $\mathrm{MD}^{1}$; Marion Marlinge, $\mathrm{MD}^{2}$; François Kerbaul, $\mathrm{MD}^{3}$; Noemie Resseguier, $\mathrm{MD}^{4}$; Marc Laine, MD ${ }^{1}$; Cautella, $\mathrm{MD}^{1}$; Charlotte Cordier, $\mathrm{MD}^{2}$; Benjamin Colomb, $\mathrm{MD}^{2}$; Nathalie Kipson ${ }^{5}$, Franck

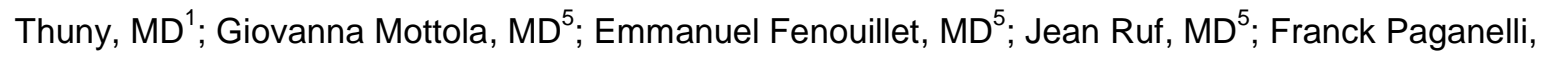
$\mathrm{MD}^{1}$; Régis Guieu, $\mathrm{MD}^{5 *}$; Laurent Bonello, $\mathrm{MD}^{* 1}$

${ }^{1}$ Assistance Publique-Hôpitaux de Marseille, Department of Cardiology, Hôpital Nord, Marseille, France; Mediterranean Academic association for Research and Studies in Cardiology (MARS Cardio), Marseille, France; Aix-Marseille University, INSERM UMR 1076, Marseille, France.

${ }^{2}$ Aix-Marseille University, UMR MD2, Marseille, France.

${ }^{3}$ SAMU, Marseille, France.

${ }^{4}$ Aix-Marseille University, EA 3279 Public Health, Chronic Diseases and Quality of Life Research Unit, Marseille, France.

${ }^{5}$ UMR MD2/AMU, Marseille, France.

*These authors contributed equally to the work.

Corresponding author: Régis Guieu, UMR MD2, Faculty of Medicine, Bvd P Dramard, 13015, Marseille, France.E-mail: guieu.regis@orange.fr

Conflicts of Interest and Source of Funding: All authors have disclosed that they do not have any potential conflicts of interest. There was no funding for this study.

Key Words: adenosine $A_{2 A}$ receptors; cardiogenic shock; heart failure; myocardial infarction

Word Count: 2837 [max 3000, not including references, tables, or figures] 


\section{ABSTRACT}

Objective: To investigate whether adenosine $A_{2 A}$ receptors $\left(A_{2 A} R\right)$ lead to vasodilation and positive inotropic function under stimulation; and whether they play a crucial role in the control of blood pressure in patients with cardiogenic shock (CS).

Design: Prospective observational study.

Setting: Monocentric, North Hopsital, Marseille, France.

Subjects: Patients with CS $(n=16)$, acute heart failure (AHF) $(n=16)$, or acute myocardial infarction (AMI) $(n=16)$; and 16 healthy controls.

Interventions: None.

Measurements and Main Results: Arterial adenosine plasma level (APL) and $A_{2 A} R$ expression were evaluated by mass spectrometry and western blot, respectively, on admission and after $24 \mathrm{~h}$. Hemodynamic parameters, including systemic vascular resistance, were also measured. Mean APL on admission was significantly higher in patients with CS $(2.74 \pm 1.03)$ versus AHF $(1.33 \pm 0.27)$ or AMI $(1.19 \pm 0.27)(p<0.0001)$. No significant correlation was found between APL and systemic vascular resistance. Mean APL decreased significantly by $24 \mathrm{~h}$ after admission in patients with CS (2.74 \pm 1.03 to $1.53 \pm 0.68 ; p<0.001)$. Mean $A_{2 A} R$ expression was significantly lower in patients with CS $(1.18 \pm 0.11)$ or AMI $(1.01 \pm 0.11)$ versus controls $(1.28 \pm 0.05)(p<0.05)$. AHF patients expressed higher mean levels of $A_{2 A} R(1.39 \pm 0.07)$ versus the other groups $(p<0.05)$.

Conclusions: We observed high APL and low $A_{2 A} R$ expression on admission in patients with $C S$ versus AHF or AMI This may contribute to the physiopathology of CS. The potential value of these results for the diagnosis and treatment of CS requires further investigation.

Word count: 253 


\section{INTRODUCTION}

The treatment of patients with cardiogenic shock (CS) remains a major challenge in cardiology. The prevalence of CS has been reported to be increasing (1-5). Although intensive care unit mortality has decreased, suggesting improved overall patient management, CS mortality remains high, close to $50 \%$ in recent studies $(2,6)$. CS is related to ventricular dysfunction in addition to multi-organ dysfunction. Development of systemic inflammation with capillary leakage, impairment of microcirculation, and inadequate vascular tone contribute to the vicious cycle of CS (6-8). The reflex mechanism of increased systemic vascular resistance (SVR) is not fully effective, as demonstrated by variable SVR, with median SVR during CS in the normal range despite vasopressor therapy in the Should we emergently revascularize Occluded Coronaries for cardiogenic SHOCK trial (7).

The pathophysiology of CS remains largely unknown. Some molecules have been shown to have a role in the systemic inflammatory response syndrome caused by myocardial infarction. These molecules have been identified as powerful prognosis markers and may represent therapeutic targets. Among them, tumor necrosis factor alpha and interleukin-6 have been shown to have a myocardial depressant action and induce coronary endothelial dysfunction, which may further diminish coronary flow (9). Adenosine - an adenosine triphosphate derivative with a hypotensive action - is released by endothelial cells and myocytes during metabolic stress $(10,11)$. Adenosine release is highly enhanced during ischemia, hypoxia, and inflammation (12), and has been implicated in hypotension induced by systemic inflammatory response syndrome (SIRS) $(13,14)$ and during septic shock (15). Adenosine impacts the cardiovascular system through its G-coupled membrane receptors, namely $A_{1} R, A_{2 A} R$, $A_{2 B} R$, and $A_{3} R(16,17)$. Adenosine stimulation of the $A_{2 A}$ receptor $\left(A_{2 A} R\right)$ leads to peripheral $(10,18)$ and coronary (19) vasodilation, and to the activation of myocardial inotropic function (20). It may thus play a crucial role in the control of blood pressure during $C S$. In fact, the increase in $A_{2 A} R$ expression has been shown to be associated with hypotension during hemodialysis (18) and during the drop in blood pressure that occurs during neurocardiogenic syncope (21). As key factors of the vascular response, adenosine and its receptors could participate in the hemodynamic disturbance observed during cardiogenic shock.

The aim of this study was to evaluate adenosine plasma level (APL) and $A_{2 A} R$ expression in patients with CS compared to those with acute heart failure (AHF) or acute myocardial infarction (AMI) and healthy controls. 


\section{MATERIALS AND METHODS}

This prospective observational study was performed at the Intensive care unit of the department of cardiology, Hopital Nord, Marseille, France (Jan-May 2017). The protocol was approved by the Ethics Committee and informed consent was obtained from every subject before inclusion.

\section{Subjects}

Equal numbers of consecutive eligible patients with CS, AHF with severely depressed left ventricular ejection fraction (LVEF) $(<35 \%)$, and AMI were enrolled. CS, AHF, and AMI were defined according to European Society of Cardiology guidelines (22).

CS was defined as persistent hypotension (systolic blood pressure $<12 \mathrm{kPa}[90 \mathrm{~mm} \mathrm{Hg}]$ or $\geq$ $30 \mathrm{~min}$ or need for vasopressor support) despite adequate filling status with signs of hypoperfusion (cold sweated extremities, oliguria, mental confusion, dizziness, narrow pulse pressure, metabolic acidosis, elevated serum lactate, elevated serum creatinine) (22) and with a reduction in cardiac index $\left(<2.2 \mathrm{~L} / \mathrm{min} / \mathrm{m}^{2}\right)(23)$. In order to obtain a homogeneous population, we only included patients with CS related to left ventricular dysfunction secondary to AMI or to advanced end-stage chronic heart failure (CHF). Patients with CS related to arrhythmias, toxins, post-partum, or right ventricular dysfunction were not included.

AHF with severely reduced ejection fraction was defined as symptoms (breathlessness, orthopnea, paroxysmal nocturnal dyspnea, reduced exercise tolerance, tiredness, increased time to recover after exercise, ankle swelling) or signs (elevated jugular venous pressure, third heart sound, hepato-jugular reflux, laterally displaced apical impulse) of worsening CHF (22) and LVEF $<35 \%$.

AMI was defined as increased or decreased high-sensitivity cardiac troponin, with at least one value above the 99th percentile of the upper reference limit and at least one of: symptoms of ischemia, new or presumed new significant ST-T wave changes or left bundle branch block on 12-lead electrocardiogram, and development of pathological Q waves on electrocardiogram. Finally, a group of 16 healthy controls ( 10 males and 6 females; mean age $63 \pm 4$ years from the medical staff and without medication) was also recruited for adenosinergic profiling. 


\section{Adenosine Plasma Level (APL) Measurement}

Sample collection has been previously described (24). Briefly, after washing out the lumen of the radial catheter with a solution of $1 \mathrm{~mL}$ of papaverine and $1 \mathrm{~mL}$ of dipyramidole, blood was withdrawn together with a cold stop solution in vacutainer tubes to prevent both adenosine uptake by red blood cells and deamination into inosine. Samples were immediately centrifuged $\left(4^{\circ} \mathrm{C}, 1500 \times \mathrm{g}\right)$.

APL was performed on admission - before the administration of any inotrope or vasopressor and after $24 \mathrm{~h}$. APL was performed as previously described by liquid chromatography-tandem mass spectrometry after extraction (25) using a Shimadzu UFLC XR system (Shimadzu, Marne la Vallée, France). The system was interfaced with an ABSciex 4500 triple quadrupole mass spectrometer (Les Ulis, France) operating with an electrospray ionization source using nitrogen.

Liquid chromatography-mass spectrometry-grade methanol and water were purchased from VWR (Fontenay-sous-Bois, France). Formic acid, adenosine, and 2-chloroadenosine were obtained from Sigma Chemical (Saint-Quentin Fallavier, France). Whatman 903 protein saver cards ${ }^{\mathrm{TM}}$ for sample collection and preparation were acquired from GE Healthcare (Cardiff, UK).

\section{$A_{2 A}$ Receptor Expression}

$A_{2 A} R$ expression measurement has been described previously $(26,27)$. Peripheral blood mononuclear cells (PBMC) were used as the expression of $A_{2 A} R$ on PBMC correlates with those measured in coronary artery and aortic tissues (28). Blood samples were collected using Vacutainer CPT tubes (Beckton Dickinson, Franklin Lakes, NJ, USA). The PBMC layer was collected after centrifugation and washed twice prior to lysis. Samples $\left(0.25 \times 10^{6}\right.$ cells $)$ were submitted to $12 \%$ polyacrylamide gel electrophoresis under reducing conditions, followed by transfer onto a polyvinylidene fluoride membrane. The filter was incubated with Adonis $(1 \mu \mathrm{g} / \mathrm{mL})$, a homemade immunoglobulin $\mathrm{M}, \mathrm{k}$ mouse monoclonal antibody directed against $A_{2 A} R(29)$. After staining, the 45-kDa bands corresponding to $A_{2 A} R$ were submitted to densitometry analysis using the Image $1.42 q$ software $(\mathrm{NIH})$ and results expressed in arbitrary units, the ratio of pixels generated by the $A_{2 A} R$ band to pixels generated by the background signal.

\section{Hemodynamic Assessment}


Hemodynamic measurements were performed by Doppler in all patients because it has been shown to provide a reliable non-invasive assessment of SVR (30). Systemic vascular resistance index (SVRI) expressed in Wood units - was determined as: (mean arterial pressure - right atrial pressure) / cardiac index (31). To convert SVRI to conventional SVR units (dynes.sec/cm ${ }^{5}$ ), this value was multiplied by 80 (31). Right arterial pressure was estimated on the basis of inferior vena cava size and its breathing-related collapsibility according to guidelines (32).

\section{Therapeutic Management}

Patients with CS received hemodynamic support with dobutamine $5 \mu \mathrm{g} / \mathrm{kg} / \mathrm{min}$, and with norepinephrine if their mean arterial pressure remained $<8.6 \mathrm{kPa}(65 \mathrm{~mm} \mathrm{Hg})$ after $30 \mathrm{~min}(22,33)$. In analogy to septic shock, the target mean blood pressure was titrated to $8.6 \mathrm{kPa}(65 \mathrm{~mm} \mathrm{Hg})(34)$. AHF patients received standard therapy with intravenous furosemide. In order to prevent skew, nitrates were not used before hemodynamic measurement.

\section{Statistical Analysis}

Continuous variables are presented as means \pm standard deviations or medians (interquartile ranges); categorical variables are presented as numbers (percentages). Comparisons between groups for continuous variables were performed using non-parametric tests: Mann-Whitney test when comparing two groups, Kruskal-Wallis test when comparing more than two groups. Comparisons for categorical variables were performed using the $\mathrm{X}^{2}$ test, when appropriate, or the Fisher's test otherwise. Paired comparisons were performed to assess the evolution of APL between time 0 and time $24 \mathrm{~h}$ using the non-parametric Wilcoxon test. Correlation between APL and SVR was estimated by a Pearson correlation coefficient, with its $95 \%$ confidence interval.

All tests were performed two-sided, and for all analyses, a $p$-value $<0.05$ was considered statistically significant. Statistical analyses were performed using $R$ software version 3.0.3.

\section{RESULTS}

\section{Study Population}

Sixteen patients were admitted for CS: seven related to an AMI and nine related to advanced endstage $\mathrm{CHF}$ (dilated cardiomyopathy, $n=3$; ischemic heart disease, $n=3$; and valvular heart disease, 
$n=3$ ). The other two patient groups were composed of 16 patients with AHF related to reduced LVEF without cardiogenic shock and 16 patients with AMI. Baseline characteristics of the study population are depicted in Tables 1-3

\section{Adenosine Plasma Level}

Mean APL was significantly higher in patients with CS $(2.74 \pm 1.03 \mu \mathrm{M})$ versus AHF $(1.33 \pm 0.27$ $\mu \mathrm{mol} / \mathrm{L})$ or AMI $(1.19 \pm 0.27 \mu \mathrm{M})(p<0.0001)$. There was a trend towards a higher mean APL in patients with CS related to AMI than in patients with CS related to advanced end-stage CHF (3.04 \pm 1.33 vs $2.44 \pm 0.59 \mu \mathrm{M} ; p=0.124)$. In addition, mean APL was significantly higher in patients with CS related to AMI than in patients with $\mathrm{AMI}$ but without shock (3.04 \pm 1.33 vs $1.19 \pm 0.27 \mu \mathrm{M} ; p<0.008$ ). Fig. 1 A shows medians (quartiles and ranges) for all patients and controls.

There was no significant correlation between APL and hemodynamic characteristics including SVR on admission (correlation coefficient $-0.21 ; 95 \%$ confidence interval -0.48 to $0.08 ; p=0.15$ ). Mean APL on admission was not significantly different between CS hospital survivors and nonsurvivors $(2.69 \pm 1.09$ and $2.87 \pm 1.00 \mu \mathrm{M}$, respectively; $p=0.67)$.

SIRS was observed in 5/7 patients presenting with CS related to AMI, and in 3/9 patients presenting with CS related to end-stage CHF (SIRS was defined when two or more of the following signs were found : body temperature abnormalities (ie $>38^{\circ} \mathrm{C}$ àr $<36^{\circ} \mathrm{C}$ ) ; persistent tachycardia $(\mathrm{HR}>90$ bets/min) ; tachypnea or hyperventilation (breathing frequency $>20 / \mathrm{min}$ or $\mathrm{PaCO} 2<32 \mathrm{mmHg}$ ) and leucocytosis or leukopenia (leukocyte count $>12 \mathrm{Gpt} / \mathrm{L}$ or $<4 \mathrm{Gpt} / \mathrm{L}$. (Muckart DJJ et al Crit Care Med 1997)

There was a trend towards a higher mean APL in CS patients presenting with SIRS than in CS patients without SIRS ( $2.99 \pm 1.23$ vs $2.42 \pm 0.67 \mu \mathrm{M}$, respectively; $p=0.19$; Fig. 1B).

The kinetics of APL under dobutamine in patients with CS is presented in Fig. 1C. Mean APL decreased significantly from admission to $24 \mathrm{~h}$ later $(2.74 \pm 1.03$ to $1.53 \pm 0.68 \mu \mathrm{M} ; p<0.0005)$ in CS patients.

\section{$A_{2 A}$ Receptor Expression}

Mean $A_{2 A} R$ expression was significantly lower in all patients with CS combined ( $1.18 \pm 0.11$ arbitrary units) versus controls $(1.28 \pm 0.05)(p<0.05)$. However, this lower median expression was mainly due 
to the patients with CS related to AMI (1.11 [0.99-1.18]; $p<0.01$ vs controls), as there was no significant difference between patients with CS related to AHF (1.26 [1.20-1.30]; $p=0.40$ vs controls). Patients with AMI without CS expressed a lower mean level of $A_{2 A} R$ than controls $(1.01 \pm 0.11 ; p<$ 0.05). Conversely, patients with AHF but without CS expressed a higher median level of $A_{2 A} R$ than controls (1.26 [1.20-1.30]; $p<0.05)$. Fig. 2A shows medians (quartiles and ranges) for all patients and controls; Fig. 2B shows an example western blot.

\section{DISCUSSION}

The main result of this study is that patients with CS exhibited an adenosinergic profile characterized by high APL and low $A_{2 A} R$ expression. Despite a limited number of subjects, the weak overlap between the values of APL found in the CS groups and the other groups results in highly statistically significant differences between these groups. High APL $(35,36)$ and high expression of $A_{2 A} R$ (37) have been previously described in patients with CHF.

The increase in APL has been attributed to the decrease in systemic blood flow that leads to tissue hypoxia $(35,36)$. Here, we found that the highest APL was found in patients with CS related to AMI. This rise in adenosine probably resulted from hypoxemia due to both failing cardiac function and myocardial ischemia. 40-44 SAUTENT Martin et al. (15) showed high APL in patients with septic shock. In the present study, we observed high levels of plasma adenosine in patients with CS compared to hemodynamically stable patients with AMI or AHF without shock. Despite the lack of a significant correlation between APL and SVR, given the role of adenosine in vascular tone modulation, the very high APL value observed here could be involved in the extreme vasodilatation observed in CS.

The lower A2AR expression observed in the CS group as a whole is mainly due to the CS-AMI sub-group. Thus it seems that two different A2AR profile exist depending on the etiology of CS. In AHF patients without CS, the priority of the adaptive response is probably to restore the myocardium inotropic function and vasodilation, which can be achieved via high A2A R expression and high APL as A2A R activation leads to both vasodilation and increased inotropic function. In contrast, in CS, the priority is to restore blood pressure, which 
could be achieved by decreasing A2A R expression. In this condition however, APL remains high due to the strong hypoxia and inflammatory process. This may explain the lower level of A2A R in CS related to CHF compared with AHF. Finally, the lower A2A R expression in the AMI without CS group may result from the longstanding CAD condition and not from the acute myocardial ischemia (see references $28,38,39$ ).

Because $A_{2 A} R$ expression measured in PBMC has been shown to correlate with that measured in heart (45) and coronary and aortic tissues (28), the low expression found in patients with CS suggests low expression level in arterial tissues. Even though the difference is small, the slightly decreased $A_{2 A} R$ expression may have strong pathophysiological consequences, as the biological response (here vasodilation) is not proportional to the fraction of bound receptors (46).

As $A_{2 A} R$ have been implicated in inotropic function (20) and vasodilation $(10,18)$, the unusual purinergic profile sets $C S$ between $A M I$ and $A H F$, which have low and high $A_{2 A} R$ expression, respectively.

We did not observe any significant correlation between APL at admission and inhospital mortality, but this may be due to our small sample size. In septic patients, APL appeared to predict clinical outcome, with much higher values being found in non-survivors (15). However, during septic shock, the combination of hypoxemia and the inflammatory process have a synergistic effect on adenosine release that leads to a very high concentration, nearly three times the level observed in the present study in patients with CS (15). High APL values could activate low-affinity $A_{2 A} R$ and $A_{2 B} R$, leading to antiadrenergic effects and irreversible vasoplegia, and may contribute to the lack of effects of vasopressors on the restoration of blood pressure.

\section{Study limitations}


As this was a monocentric study, the results may be subject to some bias. Adequately powered studies are therefore required to evaluate the diagnostic and prognostic value of APL values in patients with CS.

\section{CONCLUSIONS}

We observed high APL and low $A_{2 A} R$ expression on admission in patients with CS compared to those with AHF or AMI. These characteristics may contribute to the pathophysiology of CS.

\section{REFERENCES}

1. Goldberg RJ, Spencer FA, Gore JM, et al: Thirty-year trends (1975 to 2005) in the magnitude of, management of, and hospital death rates associated with cardiogenic shock in patients with acute myocardial infarction: a population-based perspective. Circulation 2009; 119:12111219.

2. Puymirat E, Fagon JY, Aegerter P, et al: Cardiogenic shock in intensive care units: evolution of prevalence, patient profile, management and outcomes, 1997-2012. Eur J Heart Fail 2017; 19:192-200.

3. Aissaoui N, Puymirat E, Tabone X, et al: Improved outcome of cardiogenic shock at the acute stage of myocardial infarction: a report from the USIK 1995, USIC 2000, and FAST-MI French nationwide registries. Eur Heart J 2012; 33:2535-2543.

4. Fang J, Mensah GA, Alderman MH, et al: Trends in acute myocardial infarction complicated by cardiogenic shock, 1979-2003, United States. Am Heart J 2006; 152:1035-1041.

5. Jeger RV, Radovanovic D, Hunziker PR, et al: Ten-year trends in the incidence and treatment of cardiogenic shock. Ann Intern Med 2008; 149:618-626. 
6. Thiele H, Ohman EM, Desch S, et al: Management of cardiogenic shock. Eur Heart J 2015; 36:1223-1230.

7. Kohsaka S, Menon V, Lowe AM, et al: Systemic inflammatory response syndrome after acute myocardial infarction complicated by cardiogenic shock. Arch Intern Med 2005; 165:16431650.

8. Ramanathan K, Harkness SM, Nayar AC, et al: Cardiogenic shock in patients with preserved left ventricular systolic function: Characteristics and insight into mechanisms [Abstract 887-2]. J Am Coll Cardiol 2004; 43:A241.

9. Zhang C, Xu X, Potter BJ, et al: TNF-alpha contributes to endothelial dysfunction in ischemia/reperfusion injury. Arterioscler Thromb Vasc Biol 2006; 26:475-480.

10. Sollevi A: Cardiovascular effects of adenosine in man; possible clinical implications. Prog Neurobiol 1986; 27:319-349.

11. Hack B, Witting PK, Rayner BS, et al: Oxidant stress and damage in post-ischemic mouse hearts: effects of adenosine. Mol Cell Biochem 2006; 287:165-175.

12. Grenz A, Homann D, Eltzschig HK: Extracellular adenosine: a safety signal that dampens hypoxia-induced inflammation during ischemia. Antioxid Redox Signal 2011; 15:2221-2234.

13. Kerbaul F, Collart F, Giorgi R, et al: Role of endogenous adenosine as a predictive marker of vasoplegia during cardiopulmonary bypass and postoperative severe systemic inflammatory response. Crit Care Med 2006; 34:640-645.

14. Nee L, Giorgi R, Garibaldi V, et al: Ischemia-modified albumin and adenosine plasma concentrations are associated with severe systemic inflammatory response syndrome after cardiopulmonary bypass. J Crit Care 2013; 28:747-755.

15. Martin C, Leone M, Viviand X, et al: High adenosine plasma concentration as a prognostic index for outcome in patients with septic shock. Crit Care Med 2000; 28:3198-3202.

16. Ralevic V, Burnstock G: Receptors for purines and pyrimidines. Pharmacol Rev 1998; 50:413492.

17. Fredholm BB, Arslan G, Halldner L, et al: Structure and function of adenosine receptors and their genes. Naunyn Schmiedebergs Arch Pharmacol 2000; 362:364-374. 
18. Giaime P, Carrega L, Fenouillet E, et al: Relationship between A2A adenosine receptor expression and intradialytic hypotension during hemodialysis. J Investig Med 2006; 54:473477.

19. Shryock JC, Belardinelli L: Adenosine and adenosine receptors in the cardiovascular system: biochemistry, physiology, and pharmacology. Am J Cardiol 1997; 79:2-10.

20. Monahan TS, Sawmiller DR, Fenton RA, et al: Adenosine A(2a)-receptor activation increases contractility in isolated perfused hearts. Am J Physiol Heart Circ Physiol 2000; 279:H14721481.

21. Carrega L, Saadjian AY, Mercier L, et al: Increased expression of adenosine A2A receptors in patients with spontaneous and head-up-tilt-induced syncope. Heart Rhythm 2007; 4:870-876.

22. Ponikowski P, Voors AA, Anker SD, et al: 2016 ESC Guidelines for the diagnosis and treatment of acute and chronic heart failure: The Task Force for the diagnosis and treatment of acute and chronic heart failure of the European Society of Cardiology (ESC). Developed with the special contribution of the Heart Failure Association (HFA) of the ESC. Eur Heart $J$ $2016 ; 37: 2129-2200$.

23. Reynolds HR, Hochman JS: Cardiogenic shock: current concepts and improving outcomes. Circulation 2008; 117:686-697.

24. Saadjian AY, Paganelli F, Juin MA, et al: Plasma beta-endorphin and adenosine concentration in pulmonary hypertension. Am J Cardiol 2000; 85:858-863.

25. Marlinge M, Variro D, Marolda V, et al: Rapid measurement of adenosine concentration in human blood using fixed potential amperometry: comparison with mass spectrometry and high performance liquid chromatography. $J$ Anal and Bioanal Tech:in press.

26. Franceschi F, By Y, Peyrouse E, et al: A2A adenosine receptor function in patients with vasovagal syncope. Europace 2013; 15:1328-1332.

27. Jacquin L, Franceschi F, By Y, et al: Search for adenosine A2A spare receptors on peripheral human lymphocytes. FEBS Open Bio 2013; 3:1-5.

28. Gariboldi V, Vairo D, Guieu R, et al: Expressions of adenosine A2A receptors in coronary arteries and peripheral blood mononuclear cells are correlated in coronary artery disease patients. Int J Cardiol 2017; 230:427-431. 
29. By Y, Durand-Gorde JM, Condo J, et al: Production of an agonist-like monoclonal antibody to the human A2A receptor of adenosine for clinical use. Mol Immunol 2009; 46:400-405.

30. Abbas AE, Fortuin FD, Patel B, et al: Noninvasive measurement of systemic vascular resistance using Doppler echocardiography. J Am Soc Echocardiogr 2004; 17:834-838.

31. Porter TR, Shillcutt SK, Adams MS, et al: Guidelines for the use of echocardiography as a monitor for therapeutic intervention in adults: a report from the American Society of Echocardiography. J Am Soc Echocardiogr 2015; 28:40-56.

32. Galie N, Humbert M, Vachiery JL, et al: 2015 ESC/ERS Guidelines for the Diagnosis and Treatment of Pulmonary Hypertension. Rev Esp Cardiol (Engl Ed) 2016; 69:177.

33. Levy B, Bastien O, Karim B, et al: Experts' recommendations for the management of adult patients with cardiogenic shock. Ann Intensive Care 2015; 5:52.

34. Asfar P, Meziani F, Hamel JF, et al: High versus low blood-pressure target in patients with septic shock. N Engl J Med 2014; 370:1583-1593.

35. Franceschi F, Deharo JC, Giorgi R, et al: Peripheral plasma adenosine release in patients with chronic heart failure. Heart 2009; 95:651-655.

36. Funaya $\mathrm{H}$, Kitakaze M, Node K, et al: Plasma adenosine levels increase in patients with chronic heart failure. Circulation 1997; 95:1363-1365.

37. Carrega L, Fenouillet E, Giaime P, et al: Influence of haemodialysis and left ventricular failure on peripheral $\mathrm{A}(2 \mathrm{~A})$ adenosine receptor expression. Nephrol Dial Transplant 2007; 22:851856.

38. Guieu R, Kipson N, Ruf J, et al: Low basal expression of A2A adenosine receptors and increase in adenosine plasma concentration are associated with positive exercise stress testing. Int J Cardiol 2015; 180:15-17.

39. Ruf J, Paganelli F, Bonello L, et al: Spare Adenosine A2a Receptors Are Associated With Positive Exercise Stress Test In Coronary Artery Disease. Mol Med 2016; 22:530-536.

40. Eckle T, Krahn T, Grenz A, et al: Cardioprotection by ecto-5'-nucleotidase (CD73) and A2B adenosine receptors. Circulation 2007; 115:1581-1590.

41. Kohler D, Eckle T, Faigle M, et al: CD39/ectonucleoside triphosphate diphosphohydrolase 1 provides myocardial protection during cardiac ischemia/reperfusion injury. Circulation 2007; 116:1784-1794. 
42. Garcia-Dorado D, Garcia-del-Blanco B, Otaegui I, et al: Intracoronary injection of adenosine before reperfusion in patients with ST-segment elevation myocardial infarction: a randomized controlled clinical trial. Int J Cardiol 2014; 177:935-941.

43. Stumpe T, Schrader J: Phosphorylation potential, adenosine formation, and critical PO2 in stimulated rat cardiomyocytes. Am J Physiol 1997; 273:H756-766.

44. Decking UK, Schlieper G, Kroll K, et al: Hypoxia-induced inhibition of adenosine kinase potentiates cardiac adenosine release. Circ Res 1997; 81:154-164.

45. Varani K, Laghi-Pasini F, Camurri A, et al: Changes of peripheral A2A adenosine receptors in chronic heart failure and cardiac transplantation. FASEB J 2003; 17:280-282.

46. Nickerson M: Receptor occupancy and tissue response. Nature 1956; 178:697-698. 


\section{Figure legends}

Figure 1. A, Adenosine plasma level (APL) at admission. B, Comparison of APL at admission depending on presence of systemic inflammatory response syndrome (SIRS). C, Kinetics of APL between admission and $24 \mathrm{~h}$. Box plots represent median, 25th and 75th percentiles; whiskers represent ranges. ${ }^{*} p<0.05$ versus controls; $\uparrow p<0.05$ versus patients without cardiogenic shock (CS). $\mathrm{AHF}=$ acute heart failure, $\mathrm{AMI}=$ acute myocardial infarction, $\mathrm{CHF}=$ chronic heart failure.

Figure 2. A, $A_{2 A}$ receptor $\left(A_{2 A} R\right)$ expression in patients and controls. B, Examples of western blot. Expression level was performed using western blot. Results are expressed in arbitrary units (ratio of pixels generated by the $A_{2 A} R$ band to pixels generated by the background signal). Box plots represent median, 25th and 75 th percentiles; whiskers represent ranges. ${ }^{*} p<0.05$ versus controls. AHF $=$ acute heart failure, $\mathrm{AMI}=$ acute myocardial infarction, $\mathrm{CHF}=$ chronic heart failure, $\mathrm{CS}=$ cardiogenic shock, . 
